\title{
Attitudes of Young Adults to Prenatal Screening and Genetic Correction for Human Attributes and Psychiatric Conditions
}

\author{
Karen K. Milner, ${ }^{1}$ Elizabeth E. Collins, ${ }^{2}$ Geoffrey R. Connors, ${ }^{2}$ and Elizabeth M. Petty ${ }^{2,3 *}$ \\ ${ }^{1}$ Department of Psychiatry, The University of Michigan Medical Center, Ann Arbor, Michigan \\ 2Department of Internal Medicine, The University of Michigan Medical Center, Ann Arbor, Michigan \\ ${ }^{3}$ Department of Human Genetics, The University of Michigan Medical Center, Ann Arbor, Michigan
}

\begin{abstract}
With recent advances in DNA technology, questions have arisen as to how this technology should be appropriately used. In this article, results obtained from a survey designed to elicit attitudes of college students to prenatal testing and gene therapy for human attributes and psychiatric conditions are reported. The eleven hypothetical disease phenotypes included schizophrenia, alcoholism, tendency toward violent behavior, attention deficit/hyperactivity disorder, depression requiring medical treatment, obesity, involvement in "dangerous" sports activities, homosexuality, borderline normal IQ (80-100), proportional short stature, and inability to detect perfect pitch. Most students supported prenatal genetic testing for psychiatric disorders and behavior that might result in harm to others (i.e., tendency towards violent behavior) and found prenatal genetic testing for human attributes less desirable. However, the lack of unilateral agreement or disagreement toward any one condition or attribute suggests the potential difficulties ahead in the quest for guidelines for the application of new technologies available to manipulate the human genome. Am. J . Med. Genet. 76: 111-119, 1998. $\odot 1998$ Wiley-Liss, Inc.
\end{abstract}

KEY WORDS: attitudes; genetic screening; gene therapy; human attributes; psychiatric disorders

*Correspondence to: Dr. Elizabeth M. Petty, Division of Molecular Medicine and Genetics, Department of I nternal Medicine, 4301 MSRB III, Box 0638, The University of Michigan Medical Center, Ann Arbor, MI 48109-0638.

Received 13 J anuary 1997; Accepted 30 J une 1997

\section{INTRODUCTION}

Advances in DNA technology during this decade have made it possible to screen for several specific monogenic disorders in utero. Precise prenatal diagnosis is readily available for several disorders that have significant morbidity and mortality in early life. Genes that predispose to adult-onset neurological disorders and to adult-onset cancers have also been localized. Genes predisposing to psychiatric disorders are actively being sought [Reus et al., 1997; Smalley, 1997], and in the recent past, genes predisposing to several human attributes, e.g., male homosexuality [Hamer et al., 1993; Hu et al., 1995] and "novelty seeking" behavior [Cloninger et al., 1996] have been localized. In addition, researchers continue to work toward developing gene therapy, or in the case of behavior attributes, genetic enhancement, which could result in the ability to treat disease or modify an attribute in the unborn child. These advances engender awe, excitement, and apprehension in the scientific community and the public alike-awe and excitement as to the potential for treating or preventing disease, apprehension as to how to determi ne appropriate guidelines for the application of so powerful a tool.

Singer [1991] looked at public opinion toward prenatal genetic testing obtained by a telephone survey and found that approximately two thirds of respondents favored testing. The respondents favoring testing tended to be younger, better educated, and more informed about science and health news. They also tended to split in terms of abortion for fetal abnormality, therefore half wanting and half not wanting abortion secondary to a positive test. Various authors have sought to elicit attitudes of specific populations (i.e., affected individuals, parents, relatives, health care professionals, or the general public) to prenatal testing and/or gene therapy for certain specific disease states, i.e., cystic fibrosis [Boué et al., 1991; Conway, et al., 1994; Decruyenaere et al., 1992; Durfy et al., 1994; Green, 1992; Mennie et al., 1993; Miller and Schwartz, 1992; Mitchell et al., 1993; Watson et al., 1991, 1992]; Huntington disease [Adam et al., 1993; Firth and Lindenbaum, 1992; Thomassen et al., 1993]; Alport syndrome 
[Levy et al., 1994]; breast, ovarian, and colonic cancer [Lerman et al., 1995; Smith and Croyle, 1995]; adult polycystic kidney disease [Hodgkinson et al., 1990] and narcolepsy [Mignot, 1997]. However, little information is available concerning attitudes toward prenatal screening or genetic testing for human attributes or psychiatric disorders. Smith et al. [1996] surveyed individuals with mood disorder, their friends and relatives, and health-care providers to elicit attitudes towards genetic screening for bipolar disorder. They found that reproductive decisions and attitudes toward prenatal testing differed markedly between the relatives and health care providers. Psychiatrists were more likely to endorse termination of a pregnancy if informed of probable heritability of bipolar disorder, particularly when the likelihood of developing the disorder was high and the course of illness was severe. In an international survey on the perception of gene therapy, three quarters of the respondents approved of the use of gene therapy for themselves or their children; 5-7\% rejected it [Macer et al., 1995; Macer, 1992]. Proponents cited "desire to save life" or "enhance the quality of life." Opponents felt it was "unnatural" or "playing God." There was less support for the use of gene therapy for purposes of "enhancement" of physical characteristics or intelligence.

Controversy exists as to whether prenatal screening and gene therapy should be available to predict and select human attributes, as does debate around what actually constitutes a "disorder," i.e., recall the debate in the field of psychiatry in the 1970's regarding homosexuality or think back to the eugenics movement of the early half of this century. This survey sought to solicit attitudes and perceptions about genetic screening and gene testing for 11 human attributes and psychiatric phenotypes in a population of adults of childbearing age. The use of the term "attributes" reflects the difficulty in designating some of these characteristics, i.e., inability to detect perfect pitch, tendency toward violent behavior, etc., as "phenotypes" or medical "diseases." The trends elicited here will serve to help focus further studies in the perception of society toward genetic testing and manipulation of the human genome.

\section{MATERIALS AND METHODS}

Two groups of undergraduate students at the University of Michigan, 79 students in a general chemistry course for non-science majors and 68 students in a class focused on the philosophy of health care, were given a 75-minute lecture on DNA diagnosis of genetic diseases by a medical geneticist (E.M.P.). Basic concepts related to the science of genetics were defined and illustrated with clinical examples of DNA diagnostic testing for several genetic conditions, i.e., cystic fibrosis, Duchenne muscular dystrophy, Huntington disease, etc. At the end of each lecture students were asked to voluntarily complete the survey (Appendix I) designed for this pilot project. The survey asked the students to assume that a specific gene had been identified that defined a certain aspect of an individual and that a precise DNA test had been devel oped to test for the "disorder" or disease phenotype in utero. Eleven hypothetical genes and disease phenotypes were presented as shown in Table I. The students were then asked to rate their agreement to the statement, "Confidential prenatal testing should be offered and available to all individuals who want to know this information," under two different conditions: a) no "curative gene therapy" is available to "treat" the disorder or b) "curative gene therapy" is available to "treat" the disorder. Demographic data were obtained from a representative sample of the participants. The surveys were collected and responses tabulated.

\section{RESULTS}

One hundred forty-seven students completed the survey. No significant differences in results were detected between the two groups of students, and the surveys were subsequently combined for analysis. Demographic data is summarized in Table II. Most participants agreed that prenatal testing should be available at least in some circumstances for schizophrenia (77\%), alcoholism (69\%), tendency toward violent behavior (63\%), ADHD (59\%), and tendency toward depression that requires medical treatment (59\%) and unavailable for inability to detect perfect pitch (78\%), proportional short stature (74\%), "borderline" normal IQ 80-100 (69\%), homosexuality (65\%), "dangerous" sports activities (62\%), and obesity (50\%), if "curative gene therapy" was not available (Figs. 1, 2). The availability of "curative gene therapy" significantly increased the desire for prenatal testing in both ADHD (from 59 to $76 \%, P=0.018$ ) and obesity (from 50 to $65 \%$, $P=0.022$ ) (Fig. 3). Statistical significance was approached for violent behavior $(P=0.121)$, schizophrenia $(P=0.129)$, al coholism $(P=0.132)$, and clinical depression $(P=0.164)$. The percentage of respondents choosing "undecided" for any condition was generally between 2-6\% for prenatal testing in the absence of "curative gene therapy." However, for homosexuality and IQ the "undecided" percentage reached $10 \%$ and $9 \%$, respectively. The "undecided" percentage increased to $13 \%$ for homosexuality and was unchanged for IQ (9\%) in the presence of "curative gene therapy." No statistical difference was noted relative to demographics for any condition. However, there was a tendency for women to endorse testing for violent behavior more often than men. Beliefs related to abortion did not

TABLE I. Hypothetical Genes and Disease Phenotypes

\begin{tabular}{ll}
\hline Gene & \multicolumn{1}{c}{ Disease phenotype } \\
\hline Weight & Obesity \\
Sexual orientation & Homosexuality \\
Thought disorder & Schizophrenia \\
Addiction potential & Alcoholism \\
Mood & Depression requiring medical treatment \\
Height & Proportional short stature \\
Attention span & Attention deficit/hyperactivity disorder \\
Aggression & Tendency towards violent behavior \\
Risk taking behavior & "Dangerous" sports activities \\
IQ & IQ 80-100 \\
Musical ability & Inability to detect perfect pitch \\
\hline
\end{tabular}


TABLE II. Demographics $(N=63)$

\begin{tabular}{lr}
\hline & $\%$ \\
\hline Gender & \\
Female & 60 \\
Male & 40 \\
Age & \\
19-21 years old & 65 \\
16-18 years old & 32 \\
22-24 years old & 3 \\
Relationship status & \\
Single & 81 \\
Opposite sex relationship & 18 \\
Same sex relationship & 2 \\
Married & 0 \\
Divorced & 0 \\
Ethnicity & \\
Caucasian & 59 \\
Asian & 22 \\
East Indian & 6 \\
African-American & 5 \\
Hispanic & 3 \\
Mixed Race & 3 \\
Other & 2 \\
Religious background & \\
Catholic & 25 \\
Protestant & 24 \\
Other & 21 \\
J ewish & 19 \\
Agnostic & 6 \\
Muslim & 36 \\
Atheist & 3 \\
Plan to have child & 3 \\
in the future? & 30 \\
Yes & \\
Undecided & \\
No & \\
Opinion concerning termination & \\
of pregnancy & \\
Disagree with it & \\
Agree with it & \\
Undecided & \\
\hline & \\
\hline
\end{tabular}

appear to affect significantly whether participants agreed with prenatal testing in the presence or absence of "curative gene therapy"; this may be reflective of our small sample size.

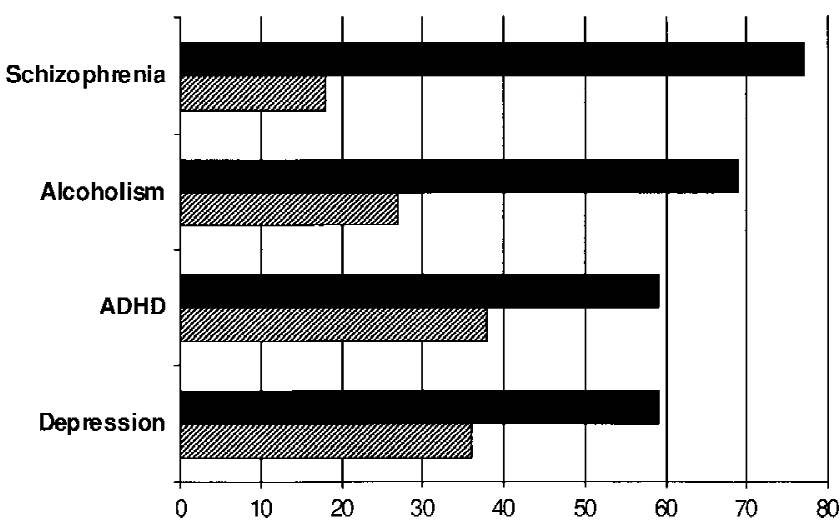

Fig. 1. Attitudes toward prenatal testing for psychiatric disorders, where the percentage of respondents who agree to prenatal testing at least in some circumstances (represented by the solid black) is compared to the percentage of respondents who disagree with prenatal testing (black and white line).

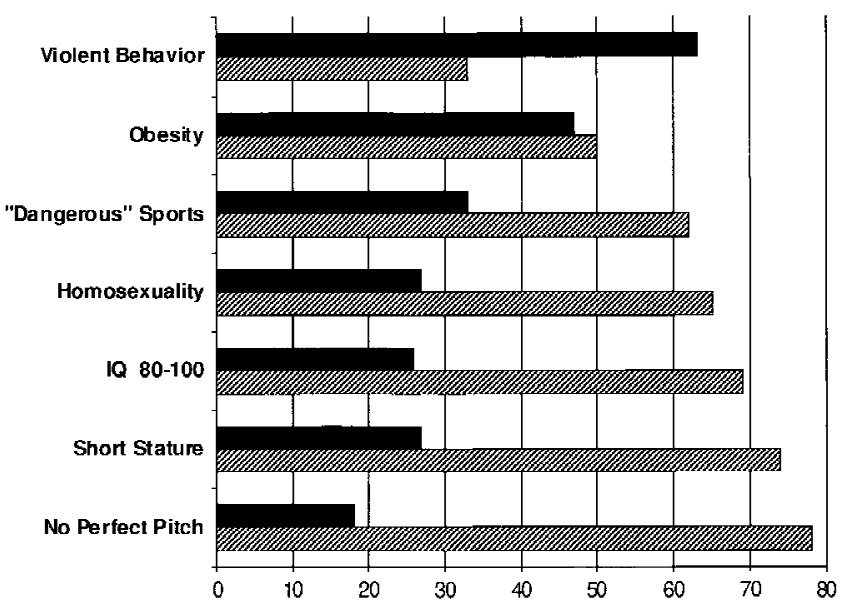

Fig. 2. Attitudes toward prenatal testing for human attributes, where the percentage of respondents who agree with prenatal testing at least in some circumstances (solid black line) is compared to the percentage of respondents who disagree with prenatal testing (black and white lines).

\section{DISCUSSION}

This survey demonstrates that most young adults of child-bearing age support prenatal genetic testing for psychiatric disorders and behavior that may result in harm to others, i.e., tendency towards viol ent behavior, and find prenatal genetic testing for human attributes less desirable. The percentage of students that was supportive of prenatal testing for accepted psychiatric disorders, i.e., 59-77\%, reflects percentages present in the literature relative to prenatal genetic testing for cystic fibrosis in a similar age group [Durfy et al., 1994]. Not surprisingly, reasons cited for the endorsement of prenatal genetic testing included the "seriousness of the disorder" or "the threat to health." Other students endorsed prenatal genetic testing for psychiatric disorders "so that the parents could be prepared" or "so that the individual could take preventative measures".

Students also endorsed prenatal testing for behavior

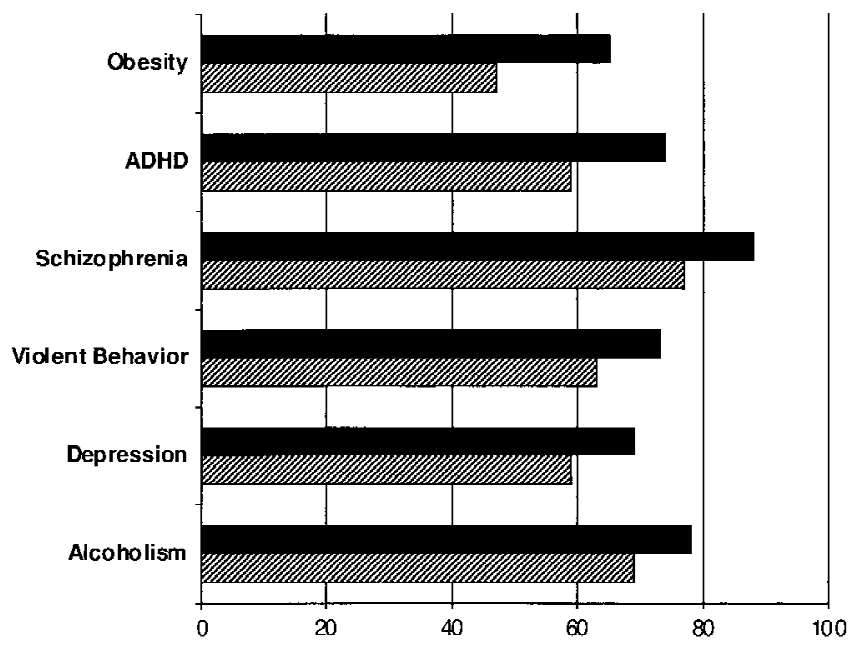

Fig. 3. Percentages of respondents who agree with prenatal testing for a specific disease phenotype in at least some circumstances in the presence (solid black line) or absence (black and white line) of curative genetherapy. 
that might result in harm to others citing a "benefit to society" or reduction in the crime rate. The fact that more women than men endorsed prenatal genetic testing for "tendency towards violent behavior" may reflect awareness of, or having been a party to, violence directed towards women. It is somewhat surprising that out of all the psychiatric phenotypes presented in this survey, statistical significance was seen in ADHD rather than mood disorder or schizophrenia. This may reflect the importance of the ability to learn and concentrate for this population of students, and/or a lack of familiarity with the symptoms of mood disorder or schizophrenia at this point in their lives.

Students were less likely to endorse prenatal genetic testing for behavioral attributes for a variety of reasons. Overall the behavioral attributes were not considered to be "a health problem" or "life-threatening." To quote one student, "Characteristics such as obesity, height, and IQ, while important to eventual selfidentification and self-confidence, pose no real threat to health." Another wrote: "Five of the mutant phenotype descriptions that should not be tested for before birth include weight, sexual orientation, height, IQ, and musical ability, because these relate to phenotypes that may be prejudiced or deemed unacceptable by society or individuals, but are not necessarily incorrect or wrong, and are not harmful." Although the two students quoted did not recognize obesity as a major health risk, many of the students did characterize obesity as a disease for which treatment would be beneficial. The need to recognize and value diversity was also frequently cited when students were asked why they disagreed with testing for behavioral attributes. One student wrote the following in regard to prenatal testing for behavioral attributes: "I feel that we would run into a situation where we were tampering with peoples' genes in order to create a more 'perfect person' ". Another stated: "What would set us apart from each other if we tried to make us all the same in abilities that give us different meaning in life and different directions?"

The number of "undecided" responses to items related to IQ and homosexuality may be construed as reflective of uncertainty on the part of some students as to whether these items constitute either behavioral attributes or disease. One student wrote the following regarding prenatal testing for IQ: 'The 'intelligence' which is measured by IQ tests is cultural. I do not believe that a way to truly measure 'intelligence' will ever be developed. Perhaps the child will not become a professional in a field of work, but that does not make him/her any less of a person than someone who does. I think that this would be a way of creating the culturally-chosen 'perfect person.' "I n regard to homosexuality, one student wrote: "I do not think that prenatal DNA testing should be allowed or developed for homosexuality because it should not be considered a disease that needs to be cured. It is an individual's own personal choice to be a homosexual or not, and no one should be criticized or forced to change a decision on how he/she wants to live their life." Another wrote: "To ask if prenatal DNA testing should be done and say that we could treat and improve this is to assume that sexual orientation is innate. I don't completely agree with this."

However, it is interesting to note that unilateral agreement or disagreement toward any one condition did not exist. For example, $18 \%$ of the students supported prenatal genetic testing for "inability to detect perfect pitch" citing "the parents' right to know." Likewise, a number of the students disagreed with prenatal genetic testing for any condition calling manipulation of the human genome "eugenics" or "playing God." In the words of one of the students: "By our very nature, we are not perfect."

The responses to this survey are similar to comparable surveys in the literature. Respondents were more likely to endorse prenatal testing and gene therapy for phenotypes that they felt to be indicative of pathology as opposed to a human attribute that is part of "normal" human diversity. Likewise, in Smith et al . [1996], decisions and attitudes toward presymptomatic testing in children depended in part on presumed severity of illness and the availability of as yet undetermined strategies that might attenuate or prevent the severity or course of the illness. Parental decisions to terminate pregnancy following abnormal cytogenetic prenatal diagnosis were found to be influenced more by the severity of the anomaly then by the length of the pregnancy [Evans et al., 1996].

The range of responses elicited from this group of students illustrate the potential difficulties ahead as we seek to come to some consensus for the application of new technologies in genetics. They highlight the moral and social arguments being debated by ethicists and health professionals in the behavioral genetics literature. These arguments seek to balance the obligation to disclose information and the fear that increased knowledge will result in limitation of group diversity and individual differences by rejection of undesired characteristics, i.e., inability to detect perfect pitch, female sex, etc. [Botkins 1990; Wertz et al. 1989]. One of the students summarized this himself when he wrote: "There is no problem with testing. The problems surface in what people do with the information that they receive." The American Society of Human Genetics recently published a statement that reviews past accomplishments and suggests future directions [Sherman et al., 1997]. The authors acknowledge the complexity of the issues, as well as the obligation of professionals to address them. To quote, "In genetic counseling, the fundamental approach is commitment to provide thorough information to clients, in understandable language. In the case of research on group differences and in the broader range of human behavioral-genetic research, there is an obligation to participate in educating the public in non-technical language, about the complexity of human traits, as well as about the simple facts of human variation. This obligation entails participation in public education programs, whether through the media, through classroom interaction, or through personal presentations to public or private interest groups." The diverse and often conflicting response of the students completing our survey underscore the complexity of these issues and highlight the 
challenges inherent in developing consensus guidelines or policy for genetic testing for psychiatric conditions and behavioral attributes. Broader studies that seek to elicit societal attitudes and moral values regarding prenatal genetic testing and in utero gene therapy will be invaluable in the development of guidelines to govern the application of genetic technology.

\section{ACKNOWLEDGMENTS}

The authors thank Ms. Ila Atwood and Ms. J anis Marchyok for their assistance in preparation of this manuscript.

\section{REFERENCES}

Adam S, Wiggins S, Whyte $P$, Bloch $M$, Shokeir $M H$, Soltan $H$, Meschino W, Summers A, Suchowersky O, Welch J P, Huggins M, Theilmann J, Hayden MR (1993): Five year study of prenatal testing for Huntington's disease: Demand, attitudes, and psychological assessment. J Med Genet 30:549-556.

Botkin J R (1990): Prenatal screening: Professional standards and the limits of parental choice. Obstet Gynecol 75:875-880.

BouéJ , Muller F, Simon-Bouy B, Faure C, Boué A (1991): Consequences of prenatal diagnosis of cystic fibrosis on the reproductive attitudes of parents of affected children. Prenat Diagn 11:209-214.

Cloninger CR, Adolfsson R, Svrakic NM (1996): Mapping genes for human personality. Nat Genet 12:3-4.

Conway SP, Allenby K, Pond MN (1994): Patient and parental attitudes toward genetic screening and its implications at an adult cystic fibrosis centre. Clin Genet 45:308-312

Decruyenaere M, Evers-Kiebooms G, Denayer L, Van den Berghe H (1992): Cystic fibrosis: Community knowledge and attitudes towards carrier screening and prenatal diagnosis. Clin Genet 41:189-196.

Durfy SJ , Page A, Eng B, Chang PL, Waye J S (1994): Attitudes of high school students toward carrier screening and prenatal diagnosis of cystic fibrosis. J Genet Couns 3:141-154.

Evans MI, Sobiecki MA, Krivchenia EL, Duquette DA, Drugan A, Hume R, J ohnson MP (1996) Parental decisions to terminate/continue following abnormal cytogentic prenatal diagnosis: "what" is still more important than "when." Am J Med Genet 61:353-355.

Firth HV, Lindenbaum RH (1992): UK clinicians' knowledge of and attitudes to the prenatal diagnosis of single gene disorders. J Med Genet 29:20-23.

Green, J M (1992): Principles and practicalities of carrier screening: Attitudes of recent parents. J Med Genet 29: 313-319.

Hamer DH, Hu S, Magnuson VL, Hu N, Pattatucci AML (1993): A linkage between DNA markers on the $\mathrm{X}$ chromosome and male sexual orientation. Science 261:321-327.

Hodgkinson KA, Kerzin-Storrar L, Watters EA, Harris R (1990): Adult polycystic kidney disease: knowledge, experience, and attitudes to prenatal diagnosis. J Med Genet 27:552-558.

Hu S, Pattatucci AML, Patterson C, Li L, Fulker DW, Cherny SS, Krug- lyak L, Hamer DH (1995): Linkage between sexual orientation and chromosome Xq28 in males but not in females. Nat Genet 11:248-256.

Lerman C, Seay J , Balshem A, Audrain J (1995): Interest in genetic testing among first-degree relatives of breast cancer patients. Am J Med Genet 57:385-392.

Levy M, Pirson Y, Simon P, Boudailliez B, Nivet H, Rance N, Moynot A, Broyer M, Grunfeld J P (1994): Evaluation in patients with Alport syndrome of knowledge of the disease and attitudes toward prenatal diagnosis. Clin Nephrol 42:211-220.

Macer DR (1992): Public acceptance of human gene therapy and perceptions of human genetic manipulation. Hum Gene Ther 3:511-518.

Macer DRJ , Akiyama S, Alora AT, Asada Y, Azariah J, Azariah H, Boost MV, Chatwachirawong P, Kaushik V, Leavitt FJ , Macer NY, Ong CC, Srinives P, Tsuzuik M (1995): International perceptions and approval of gene therapy. Hum Gene Ther 6:791-803.

Mennie M, Compton M, Gilfillan A, Axton RA, Liston WA, Pullen I, Whyte D, Brock DJ (1993): Prenatal screening for cystic fibrosis: Attitudes and responses of participants. Clin Genet 44:102-106.

Mignot E. (1997): BEHAVIORAL GENETICS '97 Genetics of narcolepsy and other sleep disorders. Am J Hum Genet 60:1289-1302.

Miller SR, Schwartz RH (1992): Attitudes toward genetic testing of Amish, Mennonite, and Hutterite families with cystic fibrosis. Am J Public Health 82:236-242.

Mitchell J, Scriver CR, Clow CL, Kaplan F (1993): What young people think and do when the option for cystic fibrosis carrier testing is available. J Med Genet 30:538-542.

Reus VI, Freimer NB. (1997): BEHAVI ORAL GENETICS '97 Understanding the genetic basis of mood disorders: Where do we stand? AmJ Hum Genet 60:1283-1288.

Sherman SL, DeFries J C, Gottesman II, Loehlin J C, Meyer J M, Pelias MZ, Rice J, Waldman I (1997): BEHAVIORAL GENETICS '97: ASHG STATEMENT Recent developments in human behavioral genetics: past accomplishments and future directions. Am J Hum Genet 60: 1265-1275.

Singer E (1991): Public attitudes toward genetic testing. Pop Res Policy Rev 10:235-255.

Smalley SL (1997): BEHAVIORAL GENETICS '97 Genetic influences in childhood-onset psychiatric disorders: Autism and Attention-Deficit/ Hyperactivity disorder. Am J Hum Genet 60:1276-1282.

Smith KR, Croyle RT (1995): Attitudes toward genetic testing for colon cancer risk. Am J Public Health 85:1435-1438.

Smith LB, Sapers B, Reus VI, Freimer NB (1996): Attitudes towards bipolar disorder and predictive gene testing among patients and providers. J Med Genet 33:544-549.

Thomassen, R, Tibben A, Niermeijer MF, van der Does E, van de Kamp J J , Verhage F (1993): Attitudes of Dutch general practitioners toward presymptomatic DNA-testing for Huntington disease. Clin Genet 43:6368.

Watson EK, Marchant J, Bush A, Williamson B (1992): Attitudes toward prenatal diagnosis and carrier screening for cystic fibrosis among the parents of patients in a paediatric cystic fibrosis clinic. J Med Genet 29:490-491.

Watson EK, Williamson R, ChappleJ (1991): Attitudes to carrier screening for cystic fibrosis: A survey of health care professionals, relatives of sufferers and other members of the public. Br J Gen Pract 41:237-240.

Wertz DC, Fletcher J C (1989): Fatal knowledge? Prenatal diagnosis and sex selection. Hastings Center Report 9:21-27. 


\section{APPENDIX 1: \\ Survey Questions}

Thank you for taking the time to answer these questions. We are going to ask you about your attitudes and opinions concerning prenatal testing and gene therapy for several different "disorders." Prenatal testing consists of a precise DNA test to identify the presence or absence of a specific disorder and is performed on the fetus before birth. Gene therapy consists of using genetic material (such as a gene) to correct the "disorder" in question. Please note that these are hypothetical, meaning that at present no specific DNA test or gene therapy is available for the following conditions. There are no right or wrong answers. We hope these questions will stimulate further thought and discussion.

For the following questions, assume that a specific gene has been identified which defines this aspect of an individual and a precise DNA test has been developed to test for the "disorder" in question which is in parenthesis.

\section{A. Given the assumption that no gene therapy is available to "treat" the "disorder", please check your response to the following statement:}

\section{"Confidential prenatal testing should be offered and available to all individuals who want to know this} information."

You may add comments if you wish.

1. Weight (obesity)

_ Agree __ Agree in some circumstances $\quad$ _ $\quad$ Disagree __ Undecided

Comments:

2. Attention span (attention deficit disorder or "hyperactivity")

_ Agree __ Agree in some circumstances _ _ _ Disagree _ _ Undecided

Comments:

3. Sexual orientation (homosexuality)

Agree

Agree in some circumstances

Disagree

Undecided

Comments:

4. Aggression (tendency toward violent behavior)

Agree $\_$Agree in some circumstances $\_\_$Disagree $\_\_$Undecided
Comments:

5. Risk taking behavior ("dangerous" sports activities)

_ Agree __ Agree in some circumstances __ _ _ Disagree _ _ Undecided

Comments:

6. IQ (below average but within "normal range" - IQ 80-100)

_ Agree __ Agree in some circumstances __ _ _ Disagree _ _ _ Undecided

Comments:

7. Height (proportional short stature - women $<5^{\prime} 1^{\prime \prime}$, men $<5^{\prime} 4^{\prime \prime}$ )

Agree $\quad$ _ Agree in some circumstances $\quad \_$Disagree ___ Undecided

Comments: 
8. Musical ability (cannot detect perfect pitch)

Agree $\_$Agree in some circumstances $\_$Disagree $\_\_$Unde cided
Comments:

9. Mood (tendency towards depression that requires medical treatment)

__ Agree __ Agree in some circumstances ___ Disagree __ _ Undecided

Comments:

10. Thought process (schizophrenia)

_ Agree __ Agree in some circumstances __ _ Disagree _ _ Undecided

Comments:

11. Addiction potential (alcoholism)

Agree __ Agree in some circumstances __ Disagree __ _ Undecided

Comments:

B. Given the assumption that cost-effective in utero (prenatal) gene therapy to "treat" the "disorder" exists, please check your response to the following:

"Confidential prenatal testing should be offered and available to all individuals who want to know this information."

You may add comments if you wish.

1. Weight (obesity)

Agree $\_$Agree in some circumstances $\_$Disagree $\_$Undecided
Comments:

2. Attention span (attention deficit disorder or "hyperactivity")

_ Agree __ Agree in some circumstances ___ D _ Disagree __ Undecided

Comments:

3. Sexual orientation (homosexuality)
Agree
Agree in some circumstances
Disagree _ Undecided
Comments:

4. Aggression (tendency toward violent behavior)

$\begin{array}{lll}\text { Agree } & \text { Agree in some circumstances } \_ \text {Disagree } \_\ldots \text { Undecided } \\ \text { Comments: }\end{array}$

5. Risk taking behavior ("dangerous" sports activities)

Agree

Agree in some circumstances

Disagree

Undecided 
Comments:

6. IQ (below average but within "normal range" - IQ 80-100)

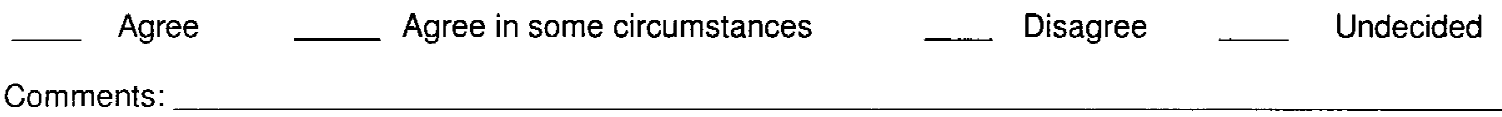

7. Height (proportional short stature - women $<5^{\prime} 1^{\prime \prime}$, men $<5^{\prime} 4^{\prime \prime}$ )

$\begin{array}{lll}\text { Agree } & \text { Agree in some circumstances } \_ \text {Disagree } \_\ldots \text { Undecided } \\ \text { Comments: } & \ldots\end{array}$

8. Musical ability (cannot detect perfect pitch)

- Agree Agree in some circumstances

Disagree _ Undecided

Comments:

9. Mood (tendency towards depression that requires medical treatment)

Agree $\_$Agree in some circumstances $\ldots$ Disagree $\ldots$ Undecided
Comments:
Thought process (schizophrenia)
Agree $\quad$ Agree in some circumstances $\quad \ldots$ Disagree __ Undecided
Comments:

11. Addiction potential (alcoholism)

$\begin{array}{lll}\text { Agree } & \text { Agree in some circumstances } \_ \text {Disagree } \_\_ \text {Undecided } \\ \text { Comments: } & \ldots\end{array}$


Because we are interested in learning what factors may influence an individual's thoughts about prenatal diagnosis and gene therapy, we would appreciate learning more about you.

Please circle or check the answer that applies to you. Your answer to this portion of the survey is voluntary. This information will be kept confidential.

1. Age: $16-18 \quad 19-21 \quad 22-24 \quad 25-28 \quad 28$ or older

2. Sex: Male Female

3. Current Relationship Status: __ Single

- Married

Divorced

Significant relationship with person of same sex

_ Significant relationship with person of opposite sex

4. Ethnicity

African-American

Hispanic

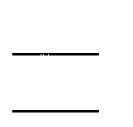

Asian

Caucasian

Mixed Race

East Indian

Native American

Other

5. Were you born in the United States?

Yes

No

If not, where were you born?

How long have you lived in the United States?

6. Were your parents born in the United States? Yes

No

7. What is the primary language spoken in your home?

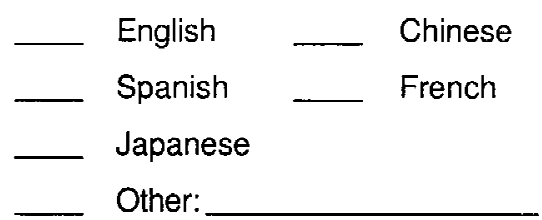

8. Religious background:

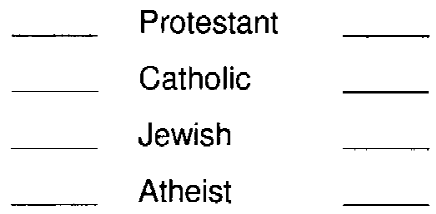

Buddhist

Muslim

Agnostic

Other

9. Do your parents share the same religious background with you? Yes

No

10. Do you have children?

Yes

No

Expecting a child

11. Do you plan to have children in the future? _ Yes

Undecided

12. What is your opinion concerning the termination of pregnancy?

Agree with it

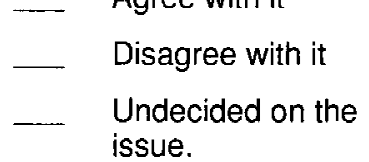

